\title{
The Rate of Decline and Trend Line Analysis of Groundwater underneath Dhaka and Gazipur City
}

\author{
Mithila Parvin \\ Bangladesh Inland Water Transport Authority (BIWTA), Dhaka, Bangladesh \\ Email: mithila.biwta@gmail.com
}

How to cite this paper: Parvin, M. (2019) The Rate of Decline and Trend Line Analysis of Groundwater underneath Dhaka and Gazipur City. Journal of Water Resource and Protection, 11, 348-356.

https://doi.org/10.4236/jwarp.2019.113020

Received: January 10, 2019

Accepted: March 22, 2019

Published: March 25, 2019

Copyright $\odot 2019$ by author(s) and Scientific Research Publishing Inc. This work is licensed under the Creative Commons Attribution International License (CC BY 4.0).

http://creativecommons.org/licenses/by/4.0/

\section{(c) (i) Open Access}

\begin{abstract}
Groundwater is reported to account for $87 \%$ of all drinking water resources in Dhaka which has suffered a decline of up to $75 \mathrm{~m}$ in some specific location. Over-extraction of groundwater is an extensive social problem in Dhaka and Gazipur city which needs to be investigating thoroughly. This study presents the diagnosis of groundwater depletion pattern and the yearly rate of decline over the last three decades for Dhaka and Gazipur metropolitan area. Groundwater data were collected from the relevant institutions in order to analyse the trend line and the rate of decline of groundwater levels for more than 30 years period to understand the long-time variability. Ten individual stations datasets for GWL have been analyzed for Dhaka and Gazipur within a selected reference time period (1980-2012). The highest depleted GWL were found in the Mirpur station which is now $68 \mathrm{~m}$ below ground. To find out the time span when the depletion rate is highest, the rate of decline of all datasets has been computed which shows that 1998-2005 is the consecutive eight years time span with the fastest depletion rate. On the other hand, the annual trend-line analysis shows rapid depletion pattern after the year 2000 .
\end{abstract}

\section{Keywords}

Groundwater Over-Exploitation, The Rate of Decline, Trend Line

\section{Introduction and Objectives}

Groundwater is prominent as the world's largest distributed store of freshwater, especially for drinking water purpose. In Bangladesh, groundwater is an important source of water for irrigation, domestic use (safe drinking water) and industrial purposes. Some $80 \%$ of irrigation originates from groundwater, particu- 
larly for the cultivation of Boro rice [1]. Intensive use of groundwater impacts on the groundwater table which has gradually declined in the north-west and north-central regions of Bangladesh. Specifically, in Dhaka city, where groundwater is reported to account for $87 \%$ of all drinking water resources, groundwater levels have suffered a decline of up to $75 \mathrm{~m}$ in some specific location [2]. In these areas, evidence indicates that recharge does not keep up with abstraction rates. To fulfill the demand of fresh drinking water for the Dhaka city dwellers, uncontrolled abstraction of groundwater has been practiced for a long time, which has created problems with sustainability with regard to the management of water resources in the city. The overall lowering of the water table over the last 38 years has been from $20-40 \mathrm{~m}$ in the upper aquifer, with an average decline of more than $1.0 \mathrm{~m} /$ year and a maximum of $3.0 \mathrm{~m} / \mathrm{year}$ in the central part of the city [2].

The purpose of this study is to find out chronological variability of GWL in Dhaka and Gazipur city because Dhaka is densely populated metro and Gazipur is the growing industrial city where water demand is increasing rapidly. The objective is to identify the trend of groundwater use in the study area and probing for an interrelation with population growth. Besides, the rate of decline analysis has been done to focus out the most vulnerable year for unsustainable abstraction.

\section{Literature Review}

Due to rapid urbanization in the city resulted in higher water demand, the water table underneath Dhaka City started to decline a long time ago. At the time period of 1965-1980, when the water table declined around 3 - $9 \mathrm{~m}$, the maximum declined found at Motijheel and minimum in the Banani area. The maximum depth to the water table in the central part of Dhaka City, i.e. the Tejgaon area, is about $67.0 \mathrm{~m}$ below the ground surface [2]. Besides, around $65.4 \mathrm{~m}$ below the ground surface at Mirpur, and $20-34 \mathrm{~m}$ below the ground surface in the Mohammadpur, Dhanmondi, and Sutrapur areas, which are close to the river periphery [2]. In this literature, the investigation of declining GWL is simply done by yearly trend line analysis.

According to The World Bank estimates made in June 2007, Dhaka is a highly dynamic city that attracts some 300,000 to 400,000 new migrants each year and projection for future population indicates that Dhaka is expected to grow to about 20 million in 2020, making it the world's third largest city on the basis of population [3]. So, it can be said that Dhaka is the world's fastest-growing megacity.

Dhaka is dependent mainly on the groundwater resources of the fluvio-deltaic Plio-Pleistocene Dupi Tila Aquifer, which provides about $87 \%$ of the total water supply [2]. Groundwater is the first choice for city dwellers as it is superior in quality to surface water. To meet the demand, about $2.0 \mathrm{Mm}^{3}$ is withdrawn daily by about 567 DTW (Deep Tube Wells) and delivered to the inhabitants by a 
2500-km-long pipeline network [2]. System loss is assumed to be more than $25 \%$. It is estimated that the volume extracted from more than 900 private deep tube wells in the city area may be more than $50 \%$ of the DWASA withdrawal [2]. The renewable recharge to the aquifer is nearly negligible if it has been compared to the exploitation of groundwater [2].

\section{Methodology}

\subsection{Case Study Area}

There are a total twenty groundwater level monitoring stations within Dhaka city from which eight stations were selected due to the continuity of the datasets [4] and matching of the available data with the reference period (1980-2012). Red dots are the location of GWL station within Dhaka city. Besides this, observed data are available for Savar and Gazipur city which are $27 \mathrm{Km}$ and $29 \mathrm{Km}$ away from Dhaka. So, in total ten GWL stations observed data is available for a more or less 30 years period. These have been analyzed to find out if there is a pattern of depletion and the maximum depletion rate period within the selected reference period of analysis. On the other hand, Population growth datasets [5] are available for six different stations to compare with the GWL pattren. Figure 1 represents the location of GWL station in the Dhaka metropolitan area.

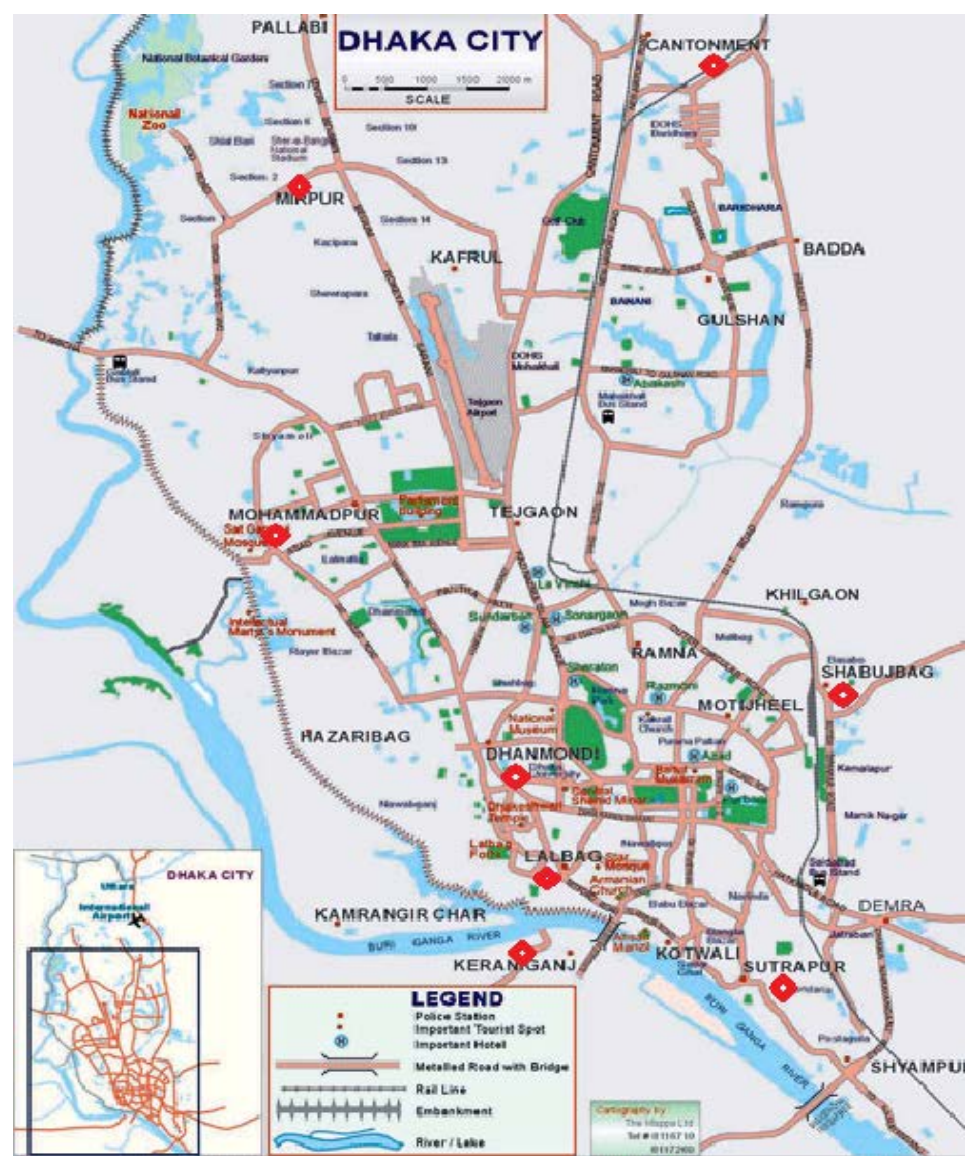

Figure 1. Location of GWL stations in Dhaka [6] (edited). 


\subsection{Groundwater Level Analysis}

In order to assess the condition of the groundwater level, there are twenty wells in Dhaka district and one well in Gazipur district monitored by Bangladesh water development board (BWDB). Weekly groundwater level data were found for the various time periods where some of the data for a few months of some years was found to be missing. For assessment, mean monthly datasets for selected reference period (1980-2012) was formulated which are passed in the error check process. Finally, ten individual mean monthly groundwater datasets were selected for evaluation.

\subsection{Annual Mean Variability}

Annual mean groundwater level (below from ground) for ten different locations within Dhaka and Gazipur districts were plotted against time to discover variability of GWL. Besides the annual mean groundwater level variability detection, the slope of the plot has been evaluated and summarized to find out when and how slopes are changing.

\subsection{Rate of Decline GWL Datasets}

It is necessary to find out the maximum depletion period for the Dupi Tila aquifer from where $87 \%$ of domestic water supply for Dhaka district has been managed. In this case, the rate of decline of GWL datasets has been done by lag time and difference method using excels spreadsheets. This difference is the change of GWL for each year which is the depletion rate per year for each set of the dataset. After formulating each dataset, the rate of decline datasets has been plotted in a single graph to identify the maximum depletion years within the reference time period.

\section{Results}

\subsection{Trend Line Analysis for Eight Stations: (Mohammadpur, Sabujbagh, Mirpur, Keraniganj, Lalbagh, Sutrapur, Savar and Gazipur)}

Regression analyses have been done for annual GWL datasets [4] to identify the change of the slope in the trend line with progressing time. Besides, decadal population growth has been compared for each available dataset [5] in every individual station. For the Mohammadpur station in Figure 2(a), the annual depletion rate is $0.7 \mathrm{~m} /$ year where the depletion rate is relatively consistent, with no sudden changes. It seems that water level is decreasing at a steady state rate over the selected time span and population growth is at a steady rate for every decade. Besides, the annual depletion rate at the Sabujbagh station in Figure 2 (b) was found to be $2.08 \mathrm{~m} /$ year and the depleting pattern of GWL is not at the same pace all over the reference period. There is a sharp slope exists within the years 1998-2001 and the slope again become flatter within the years 2002-2010 which has a resemblance with population growth pattern because the rate of 


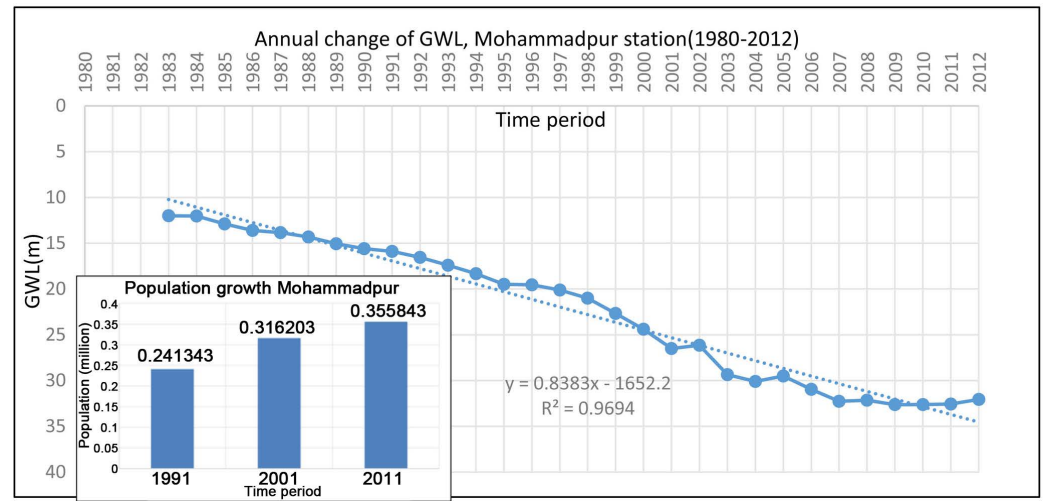

(a)

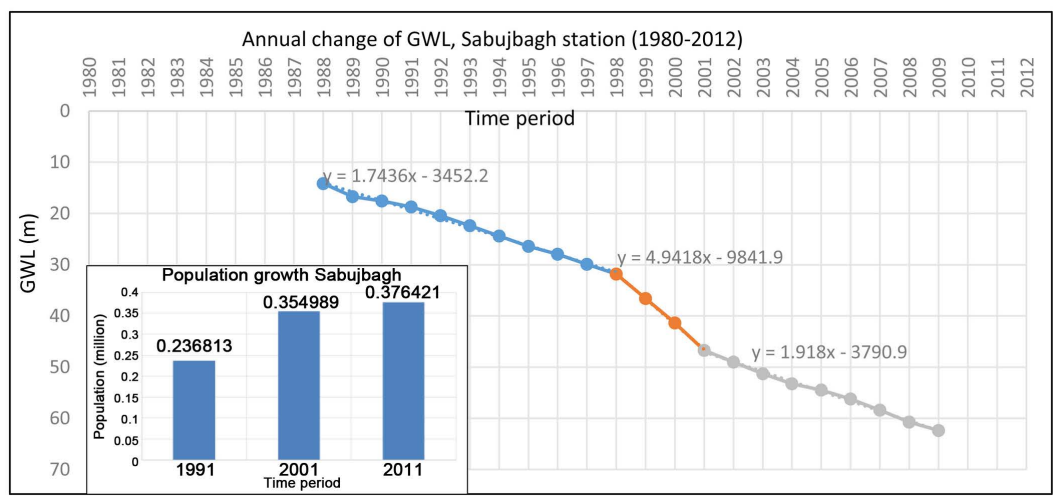

(b)

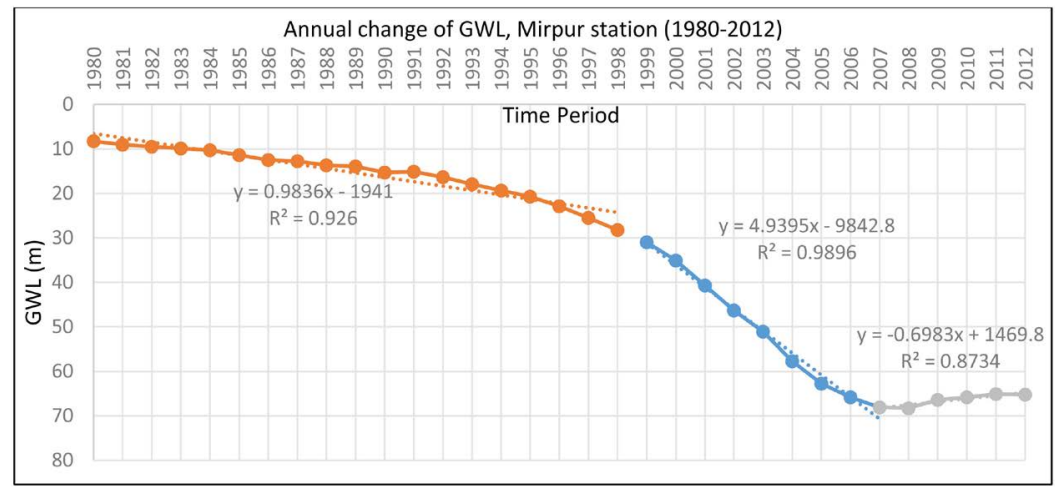

(c)

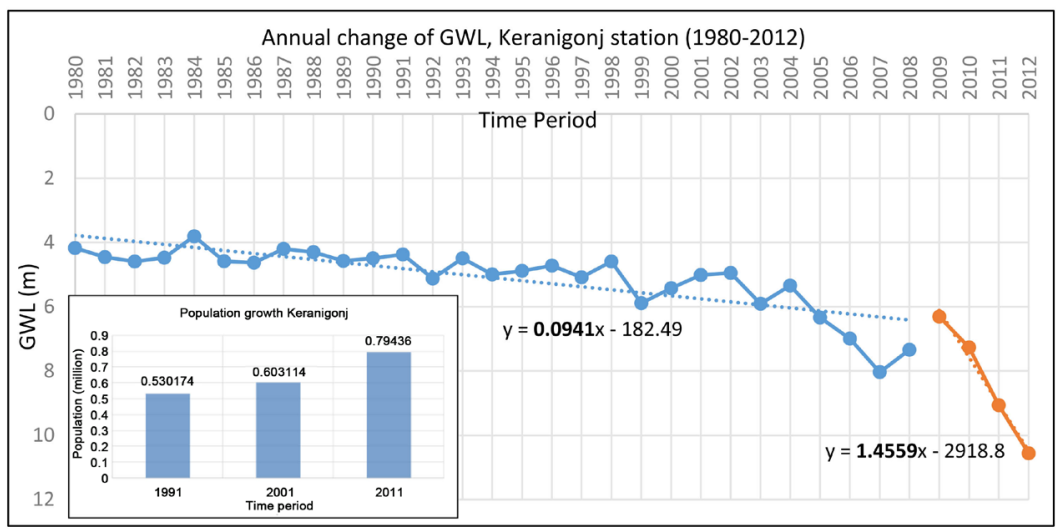

(d) 


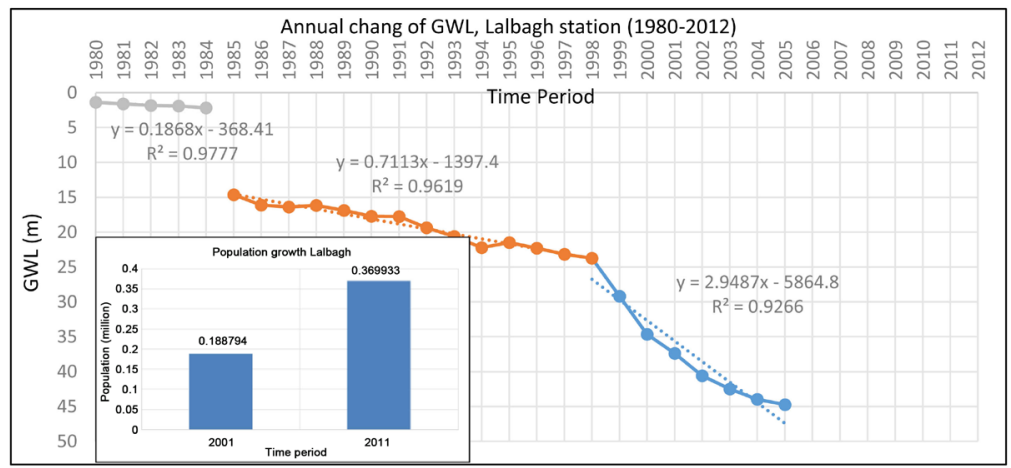

(e)

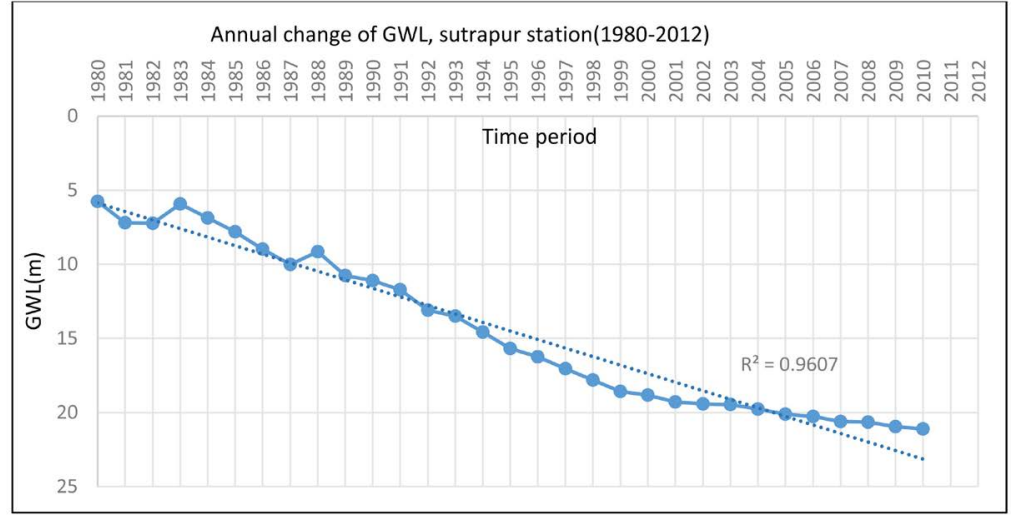

(f)

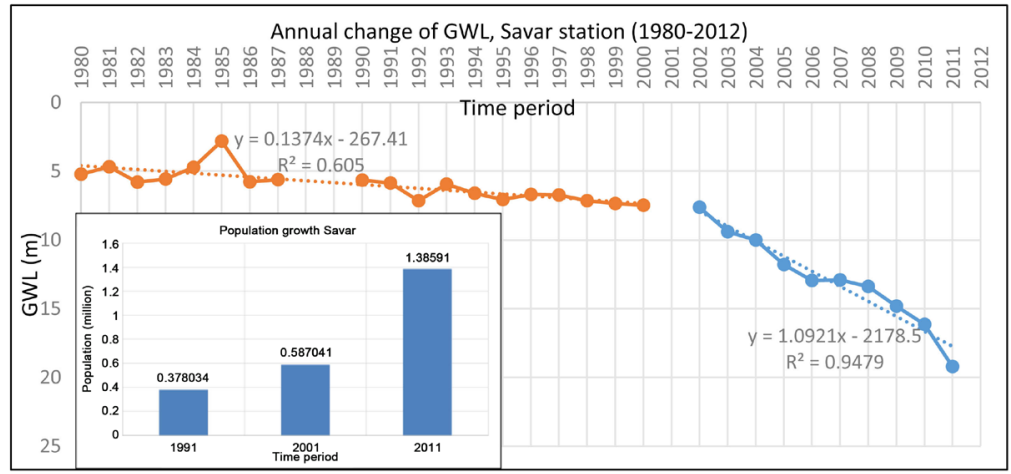

(g)

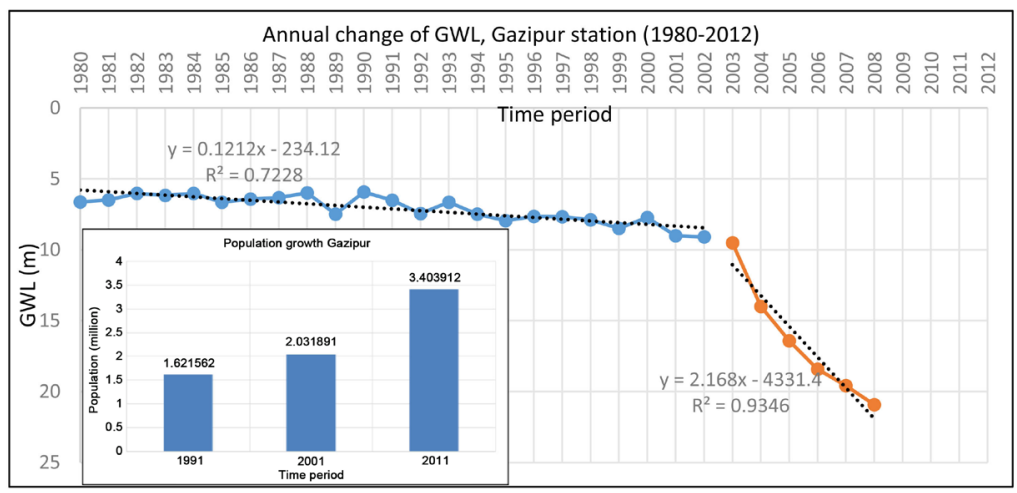

(h)

Figure 2. (a)-(h) Annual change of GWL and the population growth. 
population growth is higher in the Sabujbagh for the previous 10 years (1991-2001) rather than the last ten years (2001-2011). Again, the annual depletion rate at the Mirpur station in Figure 2(c) was found to be $1.78 \mathrm{~m} /$ year through the depletion pattern of GWL is not at the same pace for the full reference period. The slope is steeper for the years 1999-2007 and the slope again become flatter for the years 2007-2012. On the other hand, the depletion rate at the Keranigonj station was $0.2 \mathrm{~m} /$ year, which is not so high compared to others. From the trend plotted in Figure 2(d), it is visualized that from 1980 to 2009 the water level lowered only 2 m. But from 2009 to 2012 the slope is very steep. At the Lalbagh station in Figure 2(e), the annual depletion rate was $1.58 \mathrm{~m} /$ year. There is a steep slope of depletion after the year 1998. This could be attributed to the increasing population because the rate of population increase is about 18,000 persons/year for the last 10 year (2001-2011). At the Sutrapur station in Figure 2(f), the annual depletion rate was found to be $0.511 \mathrm{~m} /$ year and there is not any sharp change of slope after the year 2000, with the groundwater levels depleting at a steady rate. The population growth rate after the year 2000 is some 1933/year which is not so severe. For this station, there is a sharp change in slope after the year 2002. The slope is steeper than the previous two decades. The Savar station in Figure 2(g), the population increase rate is higher after the year 2000 rather than before, as shown in the population graph. This could be a major factor for the lowering of GWL at a very fast rate after the year 2000. For the Gazipur station in Figure 2(h), there is a sharp change of slope after the year 2003. The slope is much steeper than in the previous two decades. Besides, from the census graph, we can see how population growth rate increased after the year 2000 which may explain the impact on the GWL from which the demand may fulfill. The figure shows the annual variability and the change of slope for the GWL combining the population growth pattern [7].

From the above results and discussion, it can be concluded that for the majority of the station there is a linear correlation with the population growth of those areas whereas in some places the depletion rate become decreasing after the year 2006-07. The reason for the increasing depletion rate after the year 2000 seems to be related to the population growth which leads to higher water demand. Additionally, there is one anomaly identified within Keranigong and Sutrapur station. Both of these stations located very near to the Buriganga River but for the Keranigonj station, there is a very steep slope from the year 2009 whereas for the Sutrapur station the depletion pattern is almost smooth. Even the population growth pattern of Keranigonj couldn't explain this behavior clearly. So the question is if this is a pure population increase or if there are other reasons. It is clear that there is an increase in demand in all stations. But the pattern can also be influenced by the hydrogeological behavior of the stations. What may also influence is how deep the piezometer is (in which aquifer it is filtered). It would be suggested that detailed hydrogeological condition of each station need to be explored in future research. 


\subsection{Analysis of the Yearly Rate of Decline}

Removing a trend from the data analysis enables to focus on the fluctuations in the data about the trend. A linear trend typically indicates a systematic increase or decrease in the data. In this analysis, the rate of change of the groundwater levels is explored to find out if there are particular periods with more pronounced increases/decreases. From the rate of change pattern for ten groundwater level station, it can be seen that there is a tendency that the depletion rate increases with time. Especially after the year 1998, the depletion rate is higher. There is a sudden increase in the year 1984-85 for three different stations though these may be outliers. Finally, it can be concluded that the years 1998-2005 is the maximum GWL depletion period for the study area. Figure 3 represents the maximum depletion year for ten GWL stations within the study area [7].

\section{Conclusion}

Ten different datasets for GWL have been analyzed for Dhaka metro and Gazipur city. All of these datasets show depletion of GWL within a selected reference time period (1980-2012). The highest depleted GWL was found in the Mirpur station which is now $68 \mathrm{~m}$ below ground. The highest reasonable depletion rate was found in the same station which is 6.64 meter in one year. To find out the time period with the highest depletion rate, the rate of decline of all datasets has been computed which shows that 1998-2005 were the years with the fastest depletion. These eight years of intense abstraction leads to unsustainability in groundwater resources underneath Dhaka and Gazipur city. Finally, it can be concluded that groundwater abstraction rate is unsustainable for Dhaka and Gazipur city and 1998 to 2005 is the peak period for extra-abstraction which is a risk factor for future domestic water supply.

\section{Acknowledgements}

This research partially fulfilled the requirement of the Master of Science thesis

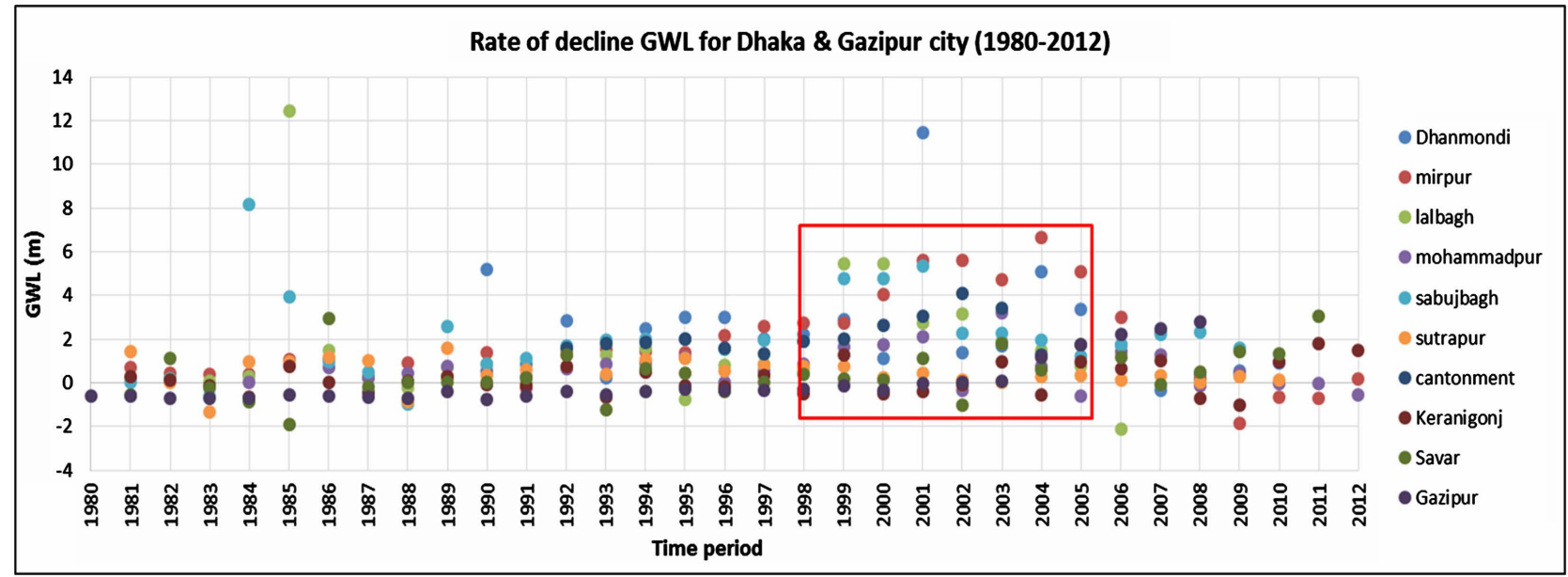

Figure 3. Accumulated results of maximum depletion rate. 
award of the author in the IHE-DELFT, Institute for water education. This research is funded by Earth to Observe (E2O) project. The author acknowledges to Dr. Micha Werner, associate professor of IHE-DELFT who is the mentor and Dr. Mario Franca, professor of IHE-DELFT who is the supervisor of this project due to their continuous support during research and Bangladesh water development board (BWDB) and Bangladesh bureau of statistics (BBS) for supplying necessary observed data.

\section{Conflicts of Interest}

The author declares no conflicts of interest regarding the publication of this paper.

\section{References}

[1] FAO (2011).

http://www.fao.org/nr/water/aquastat/water_res/index.stm

[2] Zahid, A. and Hasan, M. (2017) Management of Overexploited Dhaka City Aquifer. https://www.researchgate.net/publication/320471812

[3] World Bank (2007) The World Bank Annual Report 2007. Washington DC.

[4] GWL Mean Monthly Datasets. Bangladesh Water Development Board and Hydrology Department.

[5] Population Growth Census Datasets for 1991, 2001 and 2011 Census. Bangladesh Bureau of Statistics.

[6] Dhaka City Map. http://www.virtualbangladesh.com/the-basics/cities/dhaka/dhaka-city-map/

[7] Parvin, M. (2018) Characteristics and Occurrence of Drought and Its Role in Triggering Over-Exploitation of Groundwater Resources. Master of Science Thesis, UNESCO-IHE, Delft. 